\title{
KECENDERUNGAN POLA OKSIDASI FLAVONOID PADA KULIT BATANG DAN KAYU BATANG ARTOCARPUS SCORTECHINII KING. (MORACEAE)
}

\author{
Aliefman Hakim \\ Program Studi Pendidikan Kimia, Jurusan PMIPA \\ FKIP Universitas Mataram \\ Jl. Majapahit 62 Mataram, Indonesia \\ Email :Aliefmanhakim27@gmail.com
}

\begin{abstract}
Abstrak. Flavonoid yang terdapat dalam genus Artocarpus terdiri dari calkon, flavanon, flavon dan flavan-3ol. Gugus prenil pada flavonoid tersebut ada pada posisi C-3 dan cincin B teroksigenasi pada posisi C-4' atau C-2', C-4' atau C-2', C-4', C-5'. Selain itu prenilasi juga dapat terjadi pada posisi C-6, C-8, dan C-3'. Pola yang demikian sangat jarang ditemukan pada famili tumbuhan selain Moraceae. Kajian lebih lanjut terhadap pola oksigenasi cincin B pada bagian kulit batang dan kayu batang menjadi sangat menarik karena ditemukan kecenderungan yang dapat mewakili kedua bagian tersebut. Dari data metabolit sekunder kulit batang A. scortechinii King memperlihatkan kecenderungan pola oksigenasi pada cincin B dari kerangka flavon pada posisi 2', 4' dan 5'. Perkecualian hanya terjadi pada flavon sederhana, dimana oksigenasi terdapat pada posisi 2' dan 4' sedangkan metabolit sekunder dari kayu batang A. scortechinii King memperlihatkan kecenderungan pola oksigenasi cincin B pada posisi 2', 4'.
\end{abstract}

Kata Kunci: Artocarpus scortechinii King, prenilasi, dan flavonoid.

\section{PATTERN PREFERENCE OXIDATION OF THE FLAVONOID AT BARK AND HEART- WOOD OF ARTOCARPUS SCORTECHINII KING.(MORACEAE)}

\begin{abstract}
Flavonoid which is in gender Artocarpus consisted of the chalcon, flavanon, flavon and flavan-3ol. Prenylated of the flavonoid on position C-3 and B ring oxigenation on C-4' or C-2', C-4' or C-2', C-4', C-5'. Others prenylated also can be on position C-6, C-8, and C-3'. Such pattern is very rare found at set of relatives of plant besides Moraceae. Furthermore study to pattern of oxigenation on B ring at bark and heartwood become very attractive because found a tendency which can deputize second of the shares. From data metabolite secunder of the bark $A$. scortechinii King show the preference of pattern oxigenation of B ring from framework flavon on course 2', 4' and 5'. Exception is only became of the simple flavon, where oxigenation of there are on course 2' and 4' while metabolite secunder from heartwood $A$. scortechinii King show the tendency of pattern of oxigenation of B ring on course 2', 4'.
\end{abstract}

Keyword: Artocarpus scortechinii King, prenylated, and flavonoid.

\section{I.PENDAHULUAN}

Tumbuhan tingkat tinggi memiliki kumpulan senyawasenyawa organik yang dapat diekstraksi dan dimanfaatkan sebagai bahan mentah untuk kepentingan scientifik, teknologi dan komersial. Sebagian besar spesies tumbuhan tingkat tinggi tumbuh di daerah beriklim tropis. Indonesia sebagai salah satu negara yang beriklim tropis, memiliki keanekaragaman tumbuhan yang sangat tinggi. Indonesia memiliki 25.000 spesies tumbuhan tingkat tinggi dan $40 \%$ diantaranya merupakan tumbuhan endemik Indonesia [1]. Akan tetapi, kekayaan alam yang melimpah tersebut sebagian besar belum diteliti, dicatat dan dikaji, sehingga belum dapat dimanfaatkan secara optimal.

Dalam bidang pengobatan tradisional banyak sekali spesies yang telah dilaporkan manfaatnya, namun penelitian mengenai kandungan kimia tumbuhan yang bermanfaat tersebut belum banyak dikerjakan di Indonesia. Salah satu kelompok tumbuhan yang memiliki manfaat dalam bidang pengobatan adalah famili Moraceae, khususnya genus Artocarpus [2].

Artocarpus termasuk marga tumbuhan nangkanangkaan. Spesies tumbuhan yang termasuk dalam genus ini adalah nangka, cempedak, keluwih, dan sukun banyak dimanfaatkan baik buah, kayu, kulit, maupun getahnya. Penelitian mengenai kandungan kimia genus Artocarpus sudah banyak dilakukan. Senyawa kimia yang dilaporkan dalam genus Artocarpus antara lain kelompok triterpen, steroid, flavonoid, stilbenoid, dan lignan [3,4]. Senyawa fenolik yang merupakan senyawa paling banyak ditemukan 
dalam genus Artocarpus adalah golongan senyawa flavonoid. Senyawa fenolik tersebut dilaporkan memiliki aktivitas sebagai anti bakteri [5], anti fungal [6], anti malaria [7] dan sitotoksik [8]. Flavonoid yang terdapat dalam genus Artocarpus terdiri dari calkon, flavanon, dan flavon.

Beberapa senyawa turunan flavanon yang ditemukan dari genus Artocarpus menunjukkan pola oksigenasi yang sama pada cincin B yaitu C-4' atau C-2', 4' atau C-2', C-4',C5 ', senyawa-senyawa tersebut diantaranya yaitu artokarpanon (1), heteroflavanon A (2) yang diperoleh dari akar dan buah $A$. heterophyllus [9]. Selain itu artoindonesianin E (3) ditemukan pula dari kulit batang $A$. champeden [10]. Senyawa flavanon terprenilasi pada posisi C-6 atau C-8 telah diisolasi dari akar dan buah $A$. heterophyllus yaitu heteroflavanone C (4) [11]. diantaranya diisolasi dari A. heterophyllus yaitu norartokarpetin(8) [13].<smiles>O=c1cc(-c2ccc(O)cc2O)oc2cc(O)cc(O)c12</smiles>

(8)

Selain itu, senyawa flavon terprenilasi seperti artokarpin (9) yang terprenilasi oleh dua unit isopren dan salah satunya pada posisi C-3 serta memiliki pola 2',4'-dioksigenasi di cincin B ditemukan pada $A$. champeden [14]. Flavon lainnya terprenilasi pada posisi C-3 dengan pola trioksigenasi di<smiles>COc1cc(O)c2c(c1)O[C](c1ccc(O)cc1O)CC2=O</smiles>

(1)<smiles>COc1cc(O)c2c(c1)OC(c1c(OC)cc(OC)cc1OC)CC2=O</smiles>

(2)<smiles>COc1cc(OC)c([C@H]2CC(=O)c3c(O)cc(O)c(CC=C(C)C)c3O2)c(OC)c1</smiles><smiles>COc1cc(OC)c(C2CC(=O)c3c(O)cc(O)cc3O2)c(OC)c1</smiles>

(3)

(4)

Senyawa turunan calkon ditemukan dari A. altilis yaitu 1-(2,4-dihidroksifenil)-3-[8-hidroksi-2-metil-2-(4-methil-3pentenil)-2h-1-benzopiran-5-il]-1-propanon (5), 1-(2,4dihidroksifenil)-3-\{4-hidroksi-6,6,9-trimetil-6a,7,8,10a - cincin B ditemukan juga pada kulit batang $A$. champeden yaitu artocarpones A (10) dan artoindonesianin R (11) [7].

Senyawa piranoflavon merupakan senyawa turunan dari senyawa 3-prenil flavon, pembentukan senyawa kelompok

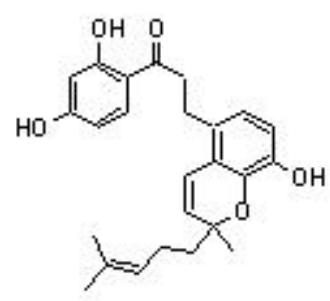

(5)

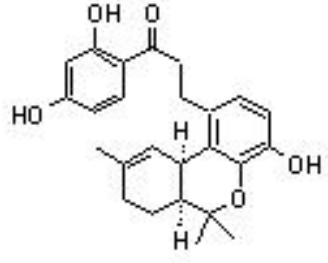

(6)<smiles>CC(C)=CCC/C(C)=C/Cc1c(CCC(=O)c2ccc(O)cc2O)ccc(O)c1O</smiles>

(7)
tetrahidro-6H-dibenzo[b,d]piran-5-il\}-1-propanon (6), dan 2-geranil-2',3,4,4'-tetra hidroksidihidrocalkon (7) [12].

Turunan flavon pada genus ini umumnya terprenilasi pada posisi C-3 dan memiliki cincin $\mathrm{B}$ teroksigenasi pada posisi C-2', C-4', dan C-5' serta beberapa senyawa turunan flavonoid ini juga terprenilasi pada C-6, C-8 dan C-3' [4]. Senyawa-senyawa flavon sederhana yang tidak terprenilasi ini secara biogenesis dapat disarankan berasal dari hasil reaksi siklisasi oksidatif yang melibatkan pembentukan ikatan $\mathrm{COC}$ antara gugus $\mathrm{OH}$ pada C-2' dengan C-9 dari gugus isopren pada C-3. Kelompok senyawa piranoflavon dari genus ini antara lain siklocampedol atau dikenal sebagai artoindonesianin (12) [15], sikloartokarpin (13), artoindonesianin A-2 (14) [7] diisolasi dari A. champeden. 


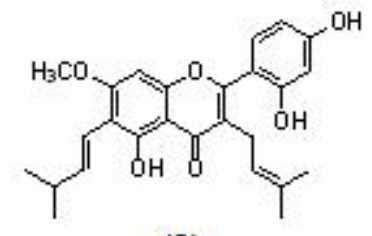

(9)<smiles>CC(C)=CCc1c(-c2cc(O)c(C)cc2O)oc2cc(O)cc(O)c2c1=O</smiles>

(10)<smiles>COc1cc(OC)c(-c2oc3cc(O)cc(O)c3c(=O)c2CC=C(C)C)cc1O</smiles>

(11)

Selain itu, senyawa piranoflavon yang telah berhasil diisolasi A. champeden, adalah heterophyllin (15),

Secara biogenesis, senyawa oksepinoflavon dapat cycloheterophyllin (16) dengan cincin piran berasal dari berasal dari senyawa 2',4'-dioksigenasi atau 2',4',5'trioksigenasi 3-prenilflavon (sebagai prekursor), melalui<smiles>CC(C)=CC1Oc2ccc(O)c(O)c2-c2oc3cc(O)cc(O)c3c(=O)c21</smiles>

(12)<smiles>CC(C)=CCc1c(-c2cc(O)c(O)cc2O)oc2c(CC=C(C)C)c3c(c(O)c2c1=O)C=CC(C)(C)O3</smiles>

(15)<smiles>CC(C)=CCc1c(O)c(CC=C(C)C)c2oc3c(c(=O)c2c1O)C(C=C(C)C)Oc1cc(O)c(O)cc1-3</smiles>

(18)<smiles>COc1cc2oc3c(c(=O)c2c(O)c1/C=C/C(C)C)C(C=C(C)C)Oc1cc(O)ccc1-3</smiles>

(13)<smiles>CC(C)=CCc1c2c(c(O)c3c(=O)c4c(oc13)-c1cc(O)c(O)cc1OC4C=C(C)C)C=CC(C)(C)O2</smiles>

(16)<smiles></smiles>

(19)<smiles>COc1cc2c(cc1O)-c1cc(O)c(O)cc1Oc1c-2oc2cc(O)cc(O)c2c1=O</smiles>

(14)<smiles>CC(C)=CCc1c(-c2cc(O)c(O)cc2O)oc2c3c(c(O)cc2c1=O)OC(C)(C)C=C3</smiles>

(17)<smiles>CC(C)=CCc1c(-c2ccc(O)cc2O)oc2c(CC=C(C)C)c3c(c(O)c2c1=O)C=CC(C)(C)O3</smiles>

(20) siklisasi prenil di C-6 dengan gugus OH di C-7. Dari kulit batang A. nobilis juga berhasil diisolasi artonin E (17) senyawa serupa hanya saja cincin piran terbentuk dari reaksi siklisasi oksidatif yang melibatkan pembentukan ikatan -C-O-C-antara gugus $\mathrm{OH}$ pada $\mathrm{C}-2$ ' dengan $\mathrm{C}-10$ dari gugus isopren pada C-3. Senyawa caplasin (21)<smiles>COc1cc2oc3c(c(=O)c2c(O)c1/C=C/C(C)C)CC(C(C)(C)O)Oc1cc(O)ccc1-3</smiles>

(21)<smiles>COc1cc2oc3c(c(=O)c2c(O)c1/C=C/C(C)C)CC(C(C)(C)O)Oc1cc(O)ccc1-3</smiles>

(22)

siklisasi prenil di posisi ( -8 dengan gugus $\mathrm{OH}$ diposisi $\mathrm{C}^{-}-7$ [16], sedangkan untuk artoheterophyllin B (18), artoheterophyllin C (19), dan artoheterophyllin D (20) berhasil diisolasi dari A. heterophyllus [17]. 


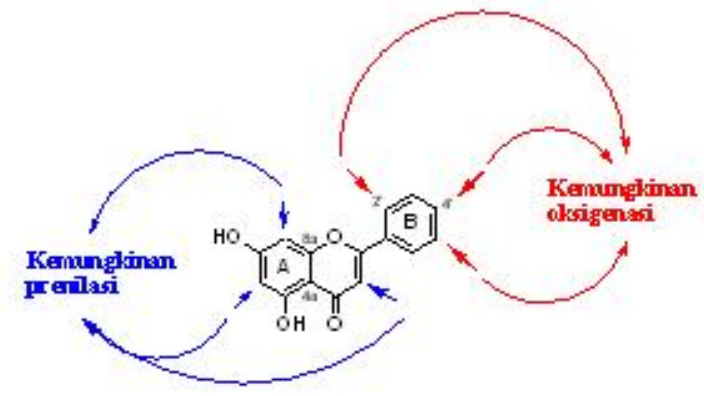

Gambar 1. Prenilasi dan oksidasi pada flavonoid [18]

merupakan senyawa golongan oksepinoflavon yang berhasil diisolasi dan dikarakterisasi dari A. champeden [14].

Gugus prenil pada flavonoid tersebut cederung berada pada posisi C-3 dan cincin B teroksigenasi pada posisi C-4' atau C-2', C-4' atau C-2', C-4', C-5'. Selain itu prenilasi juga dapat terjadi pada posisi C-6, C-8, dan C-3'. Pola yang demikian sangat jarang ditemukan pada famili tumbuhan selain Moraceae [4]. Kajian lebih lanjut terhadap pola oksigenasi cincin B pada bagian kulit batang dan kayu batang menjadi sangat menarik karena ditemukan kecenderungan yang dapat mewakili kedua bagian tersebut. Pada kajian ini akan di bahas mengenai pola oksigenasi flavonoid pada bagian kulit batang dan kayu batang Artocarpus scortechinii King yang diketahui telah berhasil disolasi beberapa senyawa flavonoid.

Tumbuhan Artocarpus scortechinii King tersebar di semenanjung Malaysia dan Sumatera dikenal dengan nama daerah terap hitam. Spesies ini sangat mirip dengan A. elasticus Reinw. tetapi memiliki daun dengan permukaan yang licin.

\section{METODOLOGIPENELITIAN}

\subsection{Bahan Tumbuhan}

Bahan tumbuhan berupa kulit batang dan kayu batang A. scortechinii King dikumpulkan dari Sarasah Bonta, Harau, Sumatera Barat. Spesies ini diidentifikasi di Herbarium Jurusan Biologi, Universitas Andalas, Padang. Bahan tumbuhan terlebih dahulu dibersihkan dari kotoran yang menempel, selanjutnya dikeringkan di bawah sinar matahari, kemudian digiling hingga berupa serbuk.

\subsection{Bahan dan Alat yang Digunakan}

Pelarut yang digunakan untuk ekstraksi dan kromatografi adalah pelarut-pelarut teknis yang sudah didestilasi yaitu $n$-heksan, $\mathrm{CHCl}_{3}$, etil asetat, aseton, dan $\mathrm{MeOH}$. Larutan jenuh $\mathrm{Ce}\left(\mathrm{SO}_{4}\right)_{2} 1,5 \%$ dalam $\mathrm{H}_{2} \mathrm{SO}_{4} 2 \mathrm{~N}$ digunakan sebagai penampak noda. Kromatografi vakum cair menggunakan Si gel Merck $60 \mathrm{G}$, kromatografi gravitasi menggunakan Si gel Merck 60 (35-70 mesh), kromatografi radial menggunakan Silika gel Merck $60 \mathrm{PF}_{254}$. Analisis kromatografi lapis tipis (KLT) dilakukan pada pelat aluminium yang berlapis Si gel Merck 60 Merck Kiesel $\mathrm{GF}_{254}$ dengan ketebalan $0,25 \mathrm{~mm}$. Pengukuran titik leleh dengan alat ukur titik leleh Fisher-John, spektrometer Varian Cary 100 Cone UV-Visible dan Shimadzu FTIR 8501 masing-masing

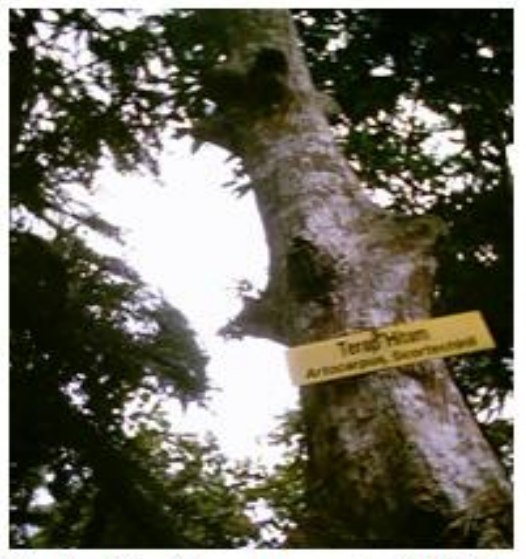

Gambar 2. Artocarpus scortechinii King

digunakan untuk mengukur spektrum UV dan IR dari senyawa hasil isolasi. Sedangkan spektrum ${ }^{1} \mathrm{H}-\mathrm{NMR}$ diukur dengan menggunakan spektrometer JEOL AS500 yang bekerja pada $500 \mathrm{MHz}$ dengan menggunakan puncak residu dan pelarut terdeuterasi sebagai standar. Selain itu digunakan juga peralatan gelas yang umum dipakai di laboratorium kimia organik.

\subsection{Cara Kerja}

Cara kerja yang dilakukan untuk memperoleh senyawa murni terdiri dari ekstraksi, pemisahan dan pemurnian dengan berbagai teknik kromatografi. Kemurnian senyawa hasil isolasi ditetapkan berdasakan analisis KLT. Penentuan struktur ditentukan dengan menggunakan metoda spektroskopi yaitu spektroskopi UV, IR, ${ }^{1} \mathrm{H}$ NMR.

Struktur flavonoid yang berhasil diisolasi dari bagian kulit batang Artocarpus scortechinii King dibandingkan dengan struktur flavonoid yang berhasil diisolasi dari bagian kayu batangnya. Perbandingan struktur flavonoid tersebut difokuskan pada pola oksigenasi cincin B dari kerangka flavonoid kedua bagian tumbuhan $A$. scortechinii King.

\section{HASIL DAN PEMBAHASAN}

\subsection{Flavonoid dari Bagian Kulit Batang}

Penelitian yang dilakukan oleh Hakim E.H., (2006) dari kulit batang Artocarpus scortechinii King. berhasil diisolasi delapan senyawa yaitu norartokarpetin (8), artonin E (17), artobiloksanton (23), sikloartobiloksanton (24), 5'kudraflavon A (25), artoindonesianin C (26), artonol A (27), dan artonol B (28). Dari penelitian tersebut terlihat bahwa metabolit sekunder yang terkandung dalam kulit batang $A$. scortechinii King. memiliki kerangka struktur yang bervariasi yaitu flavon sederhana, flavon terprenilasi, dihidrobenzosanton, furanodihidrobenzosanton, piranoflavon, siklopentenosanton, santonolid dan tetrahidrosanton. Struktur flavon yang ditemukan dari kulit batang Artocarpus scortechinii King. tersebut memperlihatkan ciri khusus yaitu oksigenasi pada cincin B dari kerangka flavon terprenilasi pada posisi 2', 4' dan 5'. Perkecualian justru pada flavon sederhana, dimana oksigenasi hanya terdapat pada posisi 2' dan 4'. 
<smiles>C=C(C)[C@H]1Cc2c(oc3c4c(cc(O)c3c2=O)OC(C)(C)C=C4)-c2c(O)cc(O)c(O)c21</smiles>

(23)

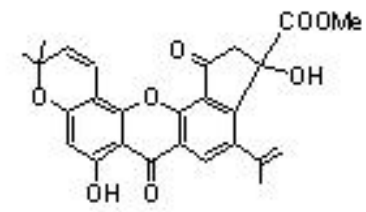

(26)<smiles>COc1cc(O)c2c3c1OC(C)(C)C3Cc1c-2oc2c3c(cc(O)c2c1=O)OC(C)(C)C=C3</smiles>

(24)<smiles>C=C(C)C1CC(=O)c2oc3cc(O)cc(O)c3c(=O)c2C1</smiles>

(27)<smiles></smiles>

(25)<smiles>CC(=O)c1c2c(cc3c(=O)c4c(O)cc5c(c4oc13)C=CC(C)(C)O5)C(C)(C)OC2=O</smiles>

(28)

\subsection{Flavonoid dari Bagian Kayu Batang}

Dari kayu batang A. scortechinii King. telah berhasil diisolasi tiga senyawa flavonoid. Senyawa flavonoid tersebut ditetapkan sebagai kudraflovon C (29) [18], artelastin (30), dan artelastisin (31) [19]. Dari penelitian posisi 2' dan 4' sedangkan dari kayu batang $A$. scortechinii King berhasil diisolasi tiga senyawa flavonoid yang ditetapkan sebagai kudraflovon C (29) [18], artelastin (30), dan artelastisin (31) [19]. Dari ketiga metabolit sekunder kayu batang $A$. scortechinii King tersebut memperlihatkan kecenderungan pola oksigenasi cincin B pada posisi 2', 4'.<smiles>CC(C)=CCc1c(O)cc2oc(-c3ccc(O)cc3O)c(CC=C(C)C)c(=O)c2c1O</smiles>

(29)

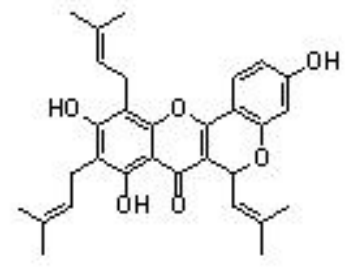

(30)<smiles>CC(C)=CCC1=C(c2ccc(O)cc2O)c2oc3c(CC=C(C)C)c(O)c(CC=C(C)C)c-3c(O)c2C(=O)C1=O</smiles>

(31)

tersebut terlihat bahwa metabolit sekunder yang terkandung dalam kayu batang $A$. scortechinii King. hanya memiliki kerangka struktur flavon terprenilasi dan piranoflavon. Struktur flavon yang ditemukan memperlihatkan ciri khusus yaitu oksigenasi pada cincin B dari kerangka flavon terprenilasi pada posisi 2', 4'. Dari data metabolit sekunder kulit batang dan kayu batang $A$. scortechinii King tersebut terlihat adanya perbedaan kecenderungan pola oksigenasi. Perbedaan tersebut menimbulkan banyak pertanyaan mengenai biogenesis metabolit sekunder yang terdapat di dalam spesies $A$. scortechinii King .

\section{IV.KESIMPULAN}

Data metabolit sekunder yang berhasil diisolasi dari kulit batang $A$. scortechinii King sejauh ini ada delapan senyawa yaitu norartokarpetin (8), artonin E (17), artobiloksanton (23), sikloartobiloksanton (24), 5'-kudraflavon A (25), artoindonesianin C (26), artonol A (27), dan artonol B (28) [10]. Dari data metabolit sekunder tersebut memperlihatkan kecenderungan pola oksigenasi pada cincin B dari kerangka flavon pada posisi 2', 4' dan 5'. Perkecualian hanya terjadi pada flavon sederhana, dimana oksigenasi terdapat pada 


\section{DAFTAR PUSTAKA}

[1] Achmad, S.A., Hakim, E. H.,. Juliawaty, L. D., Makmur., L., Kusuma, S. dan Syah, Y. M. (1995), Eksplorasi Kimia Tumbuhan Tropis Indonesia, Seminar Nasional Etnobotani II, Yogyakarta, 112-113.

[2] Heyne, K., (1987), Tumbuhan Berguna Indonesia II, Terjemahan, Penerbit Badan Litbang Kehutanan, Jakarta, 645-646

[3] Achmad, S.A., Hakim, E. H.,. Juliawaty, L. D., Makmur., L., dan Suyatno (1996), New Prenylated Flavone from Artocarpus champeden, J. Nat Prod, 59, 878-879.

[4] Nomura, T., Hano, S., and Aida M. (1998), Heterocycles, 47(2), 1179-1205

[5] Khan, M.R., Omoloso, A.D., Kihara, M., (2003) Antibacterial activity of Artocarpus heterophyllus, Fitoterapia, 74, 501-505

[6] Jayasinghe, L., Balasooriya, B.A.I.S., Padmini,W.C., Hara, N., FujimotoY. (2004), Geranyl chalcone derivatives with antifungal and radical scavenging properties from the leaves of Artocarpus nobilis, Phytochemistry, 65, 1287-1290.

[7] Widyawaruyanti, A., Subehan, Kalauni, S.K., Awale, S., Nindatu, M., Zaini, N.C., Syafruddin, D., Asih, P.B.S., Tezuka, Y., Kadota, S. (2007), New prenylated flavones from Artocarpus champeden, and their antimalarial activity in vitro, Journal Natural Medicine, 61, 410-413.

[8] Syah, Y.M., Juliawaty, L.D., Achmad, S.A,. Hakim, E.H., Ghisalberti, E.L, (2006) Cytotoxic prenylated flavones from Artocarpus champeden, Journal Natural Medicine, 60, 308-312.

[9] Lu, C. M., Chun N. L. (1993),' Two 2', 4', 6'-tryoksigenated Flavanoid from Artocarpus heterophyllus", Phytochemistry, 33(4), 909-911.

[10] Hakim, E.H., Achmad, S.A., Juliawaty, L.D., Makmur, L., Syah, Y.M., Aimi, N., Kitajima, M., Takayama, H., Ghisalberti, E.L. (2006), Prenylated flavonoids and related compounds of the Indonesian Artocarpus (Moraceae), Journal of Natural Medicine, 60, 161184.
[11] Lu, C. M., Chun N. L. (1994), Flavonoid and 9Hidroxytridecil Docosanoate from Artocarpus heterophyllus, Phytochemistry, 35(3), 781-783.

[12] Wang Y., Xu, K., Lin, L., Pan, Y., Zheng, X. (2007), Geranyl flavonoids from the leaves of Artocarpus altilis, Phytochemistry, 68, 1300-1306.

[13] Lin, C.N., Lu, C.M., Huang, P.L. (1995), Flavonoids from Artocarpus heterophyllus, Phytochemistry, 39, 14471451.

[14] Hakim, E.H., Aripin, A., Fahriyati, A., Kau, M.S., Achmad, S.A., Makmur, L., Ghisalberti, E.L., Nomura, T. (1999), Artoindonesianins A and B, Two New Prenylated Flavones from the Root of Artocarpus champeden, Journal of Natural Product, 62, 613-615.

[15] Achmad, S.A., Hakim, E. H. Juliawaty, L. D., Makmur., L., dan Suyatno (1996), New Prenylated Flavone from Artocarpus champeden, J. Nat Prod, 59, 878-879.

[16] Jayasinghe, U.L.B., Samarakoon T.B., Kumarihamy, B.M.M., Hara, N., Fujimoto Y., (2008), Four new prenylated flavonoids and xanthones from the root bark of Artocarpus nobilis, Fitoterapia, 79, 37-41.

[17] Zheng,Z.P., chen, S., Wang,S., et. al. (2009), Chemical Components and Tyrosinase Inhibitors from the Twigs of Artocarpus heterophyllus, J. Agric. Food Chem. 57, 6649-6655

[18] Hakim, A. Kudraflavon C dari kayu batang Artocarpus scortehinii King. Makalah. Disampaikan pada Seminar Nasional PMIPA FKIP Universitas Mataram. Mataram, 17 Mei 2008

[19] Hakim, A. A Prenylated Flavone From The Heartwood Of Artocarpus Scortechinii King (Moraceae). Indo. J. Chem., 2009, 9 (1), $146-150$. 